\title{
Chapter 30 \\ Finding Gender in the Arctic: A Call to Intersectionality and Diverse Methods
}

\author{
Gunhild Hoogensen Gjørv
}

\begin{abstract}
The following chapter examines multiple aspects of including gender perspectives in Arctic research. In the chapter I discuss the definition and understanding of the concept of gender, and then move to the concept of "intersectionality" which recognizes the important linkages between multiple identities of gender, race, ethnicity, class, age, and other social categories. I then discuss both the ways in which gender has been addressed, though still minimally, in Arctic research, as well as some of the ways in which Arctic research is itself gendered. I then discuss how gendered perspectives add important insights into understanding security, and more specifically human security, in the Arctic.
\end{abstract}

At the UArctic conference in St Petersburg in September 2016 I was struck, yet again, by the distinct absence of gender data and analyses, even though this conference was yet another arena whereby Arctic scientists could come together and share their continued insights into Arctic societies and environments. Though it would be unfair to claim that absolutely no one included gender insights and analysis into their research presentations at that event, there was no question that gender was not central or key to many or most research projects. Anecdotal observations and discussions with conference participants were revealing, as, when I asked some presenters about gender aspects to their research (in this case education and psychology respectively), they acknowledged the relevance of gender to their own work but did not consider raising gender as an issue in their research and presentations. Their reaction and approach was not uncommon as I continued to inquire amongst colleagues. The experience prompts me to ask, "where is gender in the Arctic?" And does our broad Arctic research community have an adequate understanding of what it means to include gender perspectives in Arctic research?

In this chapter I will address a number of issues surrounding the implementation of gender perspectives in Arctic research. I will first focus on what we mean by "gender" and further "intersectionality", that informs my argument. I follow with a discussion about the gendered nature of Arctic research, and how gender has been

\footnotetext{
G. Hoogensen Gjørv ( $ه)$

UiT The Arctic University of Norway, Troms $\emptyset$, Norway

e-mail: gunhild.hoogensen.gjorv@uit.no
} 
situated in Arctic research since the Taking Wing conference in 2002. Lastly I will use my own research to briefly illustrate how an intersectional approach (including gender, race, ethnicity, class, age, etc) is crucial to both understanding and implementing multidisciplinary and cross-cutting Arctic research.

\subsection{Definitions of Gender and Intersectionality}

\section{"Current Arctic discourses reflect a very masculine Arctic agenda" (Retter 2015)}

Integrating "gender awareness" or gender perspectives in the context of Arctic communities and research has been increasingly in focus since the early 2000s (Health 2002). Despite more than a decade of explicit attention, I would argue that gender perspectives are nevertheless still poorly understood as both a category and method in research, and thus generally marginalized in Arctic research. In this section I will draw upon gender and feminist studies literature from the field of international relations as well as upon broader feminist and gender studies research.

Gender is a primary social category used to define social and political relations. It is used in all societies though often in different ways. In general however, is rooted in, but goes beyond, the biological perception of the two sexes, male and female. The concept refers to socially constructed identities and differences between men and women, reflected in characteristics assigned to categories of "masculine" and "feminine". These roles are context and time specific, whereby different cultures and histories have their own interpretation of "man" and "woman"; the characteristics of masculine and feminine can be performed by persons of any sex category (male, female, and others), thus critiques of either masculinity or femininity are not critiques of "men" or "women" per se, but of the values, norms and practices these categories have been constructed to embody. The relationships between the resulting categories of masculinity and femininity are in constant negotiation and renegotiation (Skjelsbæk and Smith 2001).

Gender is thus a central social and political dimension by and through which human societies are based. Even those, whose research is focused on environmental changes and developments within marine, terrestrial, atmospheric or cryospheric aspects of the Arctic, have either direct or indirect impacts on human societies, including transfers of toxins into human food chains, climate change resulting in potential harms to humans such as floods, avalanches, melting of permafrost, changes in marine and terrestrial animal migration patterns, changes in ecosystems, etc. These changes can and do impact people differently based on their gender and gender roles, depending on the society in question. Societies that reflect gendered values and practices also impact Arctic science.

While Arctic science has been dominated by research methods and practices that reflect masculinist values of rationality and objectivity (often reflected in positivism), gender and feminist research has been moving beyond these research parameters to provide more comprehensive analyses of the complex relationships between the social and natural worlds. One important move in this direction was the develop- 
ment of the concept "intersectionality" recognizing that universalizing, homogenous methods and practices were often both inacurrate as well as harmful to research as well as to the societies that were central to such research. As well, universalizing definitions of gender equality and understanding of gender constructions across all societies were grossly inadequate. The three waves of feminism were dominated by experiences of generally white, middle-class, Euro/Western women, and these experiences did not speak to either the gendered norms, practices or experiences of people of colour, indigenous people, non-white-centric ethnicities and cultures, nor to those with differing experiences based on age, class, sexuality, and ability (Marfelt 2016). Coined by Kimberlé Crenshaw in the late 1980s (Crenshaw 1991), the term "intersectionality" was designed to critically assess the intersection between race and gender, and at its core has a "non-positivistic, non-essentialist understanding of differences among people as produced in on-going, contextspecific social processes" (Marfelt 2016: 32). For the rest of this chapter I will refer to the broader, more methodologically inclusive approach of intersectional analyses unless I am referring specifically to gender.

\subsection{Intersectionality and Science}

Understanding the ways in which Arctic science has been conducted is crucial to understanding how and to what degree intersectional analyses have been integrated into this body of scholarship. Intersectional research is generally part of the broader domain of social sciences, which itself has experienced "science wars", a contestation of methodologies, methods, and approaches (Keating and Della Porta 2010). Social sciences operate at high levels of abstraction, where social inquiry includes exploring ontologies, epistemologies, approaches, methodologies, and methods without predetermining the process of inquiry (ibid). As such, different processes of inquiry result in different constructions and productions of knowledge.

Feminists have long demonstrated a gendered and masculinist bias within concepts and approaches to scholarship, not least exemplified by the emphasis on rationality, objectivity, and public domains, often embodied by research in the natural sciences and visibly expressed in un-reflexive, silent authorship reinforcing "an unreflective orientation toward objectivist traditions and norms" (Gray 2017: 180). A core feature of feminist and intersectional methodological approaches therefore includes the practice of "reflexivity" whereby the researcher is "'responsible' and 'responsive' to her work and her 'subjects' of study because it makes explicit the deliberative movement of her scholarship" (Ackerly et al. 2006: 258, cited in Agathangelou and Turcotte 2008). Reflexivity allows for insight into phenomena while also illuminating how such insights were derived: "the closer an academic discipline is aligned with the natural science model the greater the pressure can be to engage in un-reflexive silent authorship" (Gray: 182). Thus, the dominance of a natural science heavy Arctic scholarship informed by objectivist methods plays a significant role in the acceptance and comprehension of what intersectional analy- 
ses bring to the discussion. My point is not to discredit objectivist/positivist types of study, as these bring necessary knowledge to light. However, Arctic research would benefit from a more substantial engagement with a plurality of methods and voices. Disciplines using an intersectional, reflexive approach have been largely relegated to "niche" research areas few are expected to tangle with, despite calls for "crosscutting" research between social and natural sciences. However, Arctic research is strengthened by providing complex insights into the broader social and political contexts in which all Arctic research takes place.

\subsection{A Glimpse into Arctic Intersectional Research}

Intersectionality tells us that gender, race, ethnicity, class, etc. are central social and political dimensions by and through which human societies are based. As noted above, research focused on environmental changes and developments within marine, terrestrial or cryospheric aspects of the Arctic, have either direct or indirect impacts on human societies. Even though there is already evidence that environmental, social, and political change can and does impact men and women differently, does the marginalization or absence of gender-focused resesarch in Arctic societies, in all their diversity, mean that Arctic societies have gender issues "figured out"? Or that Arctic policy is always "beyond" gender and it therefore does not need attention?

The still minimal, but important, intersectional research done on Arctic issues and communities would indicate that the answer to those questions should be a resounding "no". Indeed, insofar as we see gender-inclusive research, it is still quite focused on gender itself, rather than engaging an explicitly intersectional approach. In 2002, the Arctic Council conference on Gender Equality and Women in the Arctic "Taking Wing" took place, addressing a range of issues from women in the workplace including the heavily male-dominated extractive industries, living conditions, traditional knowledge and self-determination for indigenous peoples and the impacts on indigenous women, political participation, health, and violence against women (Health 2002). As the first gender-focused conference hosted by the Arctic Council, the organizers already recognized the importance of gender as a crosscutting issue, set against the backdrop of climate change and its impacts on ecosystems, globalization, cultures and peace and justice. In other words, gender in the Arctic was clearly about taking an intersectional approach, even before the notion of intersectional began to take a foothold in feminist analytical literature.

There have been a number of events or initiatives focusing on gender since 2002, including the two Arctic Human Development Reports (Einarsson et al. 2004; Larsen and Fondahl 2014), and the Gender Equality conference in 2014 which took place in Akureyri, Iceland (Oddsdóttir et al. 2015). There has been a special issue on gender published by Anthropology of East Europe Review in 2010, but like many of these other initiatives, and as I mentioned above, one can quickly get the impression that gender is a special interest or niche area rather than a broader source of data and 
an analytical resource and tool. Arctic focused conferences have generally had less of an emphasis on gender, let alone intersectionality. Ideally I, as a researcher focused in part on gender, as well as others, could argue that the reason for a lack of explicit focus on gender or intersectionality is because researchers are integrating gender analyses as a cross-cutting theme. This does not seem to be the overall case however. A quick review of more recent Arctic-themed conferences like Arctic Science Summit Week (ASSW), Arctic Frontiers, Arctic Circle, and even the International Congress of Arctic Social Sciences (ICASS) has thus far had limited focus on gender or other intersectional issues. Indeed, amongst 22 themes which consist of roughly 5-15 sessions each, originally only one session at the 2017 ICASS would explicitly addresses gender in broader understandings of Arctic societies. At the recent International Arctic Science Committee (IASC) meetings in Prague, CZ, a new gender working group was initiated, which has worked to ensure that gender will be better represented at ICASS 2017 in Umeå in June 2017, with both a panel session and a roundtable debate about gender research and gendered methods in Arctic science. Hopefully this initiative will have a spillover effect to future Arctic conferences. A review of the previous 2016 program of Arctic Circle shows that gender was not once mentioned in the program, and an email to the Arctic Frontiers secretariat asking about this was never answered.

As a further example of integrating gender perspectives into Arctic research, we can look to the first Arctic Human Development Report (Einarsson et al. 2004). Though rife with more questions than details (Oddsdóttir et al. 2015) the report was a groundbreaking achievement as an excerise in intersectionality, combining a diverse and wide-ranging group of Arctic researchers together towards creating a comprehensive overview and understanding of natural, social, and political life in the Arctic. Though not explicitly highlighting intersectionality per se, the ADHR chapter clearly illustrated the tensions between different understandings of gender in the Arctic and that one approach does not fit all. That chapter resulted in having the most co-authors of any other chapter, not least because of the broad range of issue areas that are relevant, but also because the impacts of gendered social constructions and their resulting impacts on political, social and environmental life are not universal across Arctic geographies and Arctic communities. There could not have been a better beacon to expand gender analysis in the Arctic, given the complex dynamics the ADHR Chap. 11 illustrated.

The second AHDR (Larsen/Fondahl 2014) made an explicit decision to demand that all chapter contributors address gender as a cross-cutting issue in each of the different chapter topics that were raised in the report. Not all chapters were equally successful. Remarkably the Economic Systems chapter (Chap. 4) made no mention of gender and mentioned women as a socio-economic category only briefly in one textbox. The Resource Governance chapter equally made no mention of gender, mentioning women only once, in reference to forest owners (Larsen and Fondahl 2014: 281). Indeed, an additional quick check for keywords "men", "transgender", "two-spirit" and "LGBTQ" achieved, unfortunately, no results. As noted in the 2002 "Taking Wings" report, as well as the first AHDR, economics and resources have played a significant role in the development of gender roles in communities in the 
Arctic. Natural resource and extractive industries are heavily male dominated to this day (World Bank 2015), and these industries have also been argued to be based upon masculinist value systems of exploitation that often have negative effects on the environment and climate (Miller 2004; Kawarazuka et al. 2017). The Arctic provides a hotbed of cases where extractive industries do, and will continue to contribute, to negative environmental impacts, and understanding the basis of these systems is crucial to any movement towards change.

Surprisingly, the chapter on cultures and identities was remarkably devoid of gender analysis or discussions about the role of gender in culture and identity aside from stating that more research was needed (Larsen/Fondahl 2014: 143, 144). The chapters on populations and human health and well-being were quite strong in addressing gender issues. However in general, an overriding comment amongst many of the 2014 ADHR chapter authors was that research on gender analysis was lacking and that future research needs to include these analyses (ibid). Much of the discussion revolved around statistical data as well, and did not delve deeper into the values embedded in different Arctic societies that are linked to economic development strategies, marginalization of peoples and decolonization practices, and relationships of people to the environment. This evidence does not present a strong case that we have come much farther than the 2002 "Taking Wing" conference.

\subsection{Moving Towards Intersectionality in Arctic Security Research}

How can we use an intersectional approach to illuminate social, political, and environmental developments taking place in the Arctic? In my own work on the Arctic I use both a intersectional and a security analysis approach. Both concepts are actively present politically and socially across the region, and they are intimately tied to environmental use (or exploitation) and change. The term security invokes power, whereby the utmost priorities of the person, state, social group are linked to the survival of values and practices for the future (Hoogensen Gjørv 2017). Many are quite familiar with the narrower, militarized understanding of security that focuses on the use of the military for purposes of defending one actor, the state, from existential threat (Walt 1991). However, when we think in terms of actors more broadly, and diverse practices to ensure survivial (and the diverse ways in which survival is understood), a much more complex analysis results. Through intersectional analysis, it is possible to best understand the dynamics and tensions between priorities and perceived futures for the Arctic.

This can be exemplified with the concept of "human security" which has been increasingly employed in Arctic research to articulate linkages between individual and community values and prerequisites for survival, and political and social policy. Human security was popularised in the 1994 United Nations Human Development Report, expanding the notion of security to include dimensions of food, health, 
community, environmental, economic, personal and political security, with the intention to, in part, address some of the glaring weaknesses of security theory and practice. Human security focuses on the individual as its referent. Though actively employed and debated for over two decades, there is no consenus upon a definition. Nevertheless, human security as a concept has had staying power, and is now being used in relation to the Arctic, not least demonstrated by the first edited volume that links environmental and human security in the Arctic to better understand the dynamics between nature and human, and between humans, through gendered analyses (Hoogensen Gjørv et al. 2014).

Environmental and human security (which is often informed by intersectional analyses) are concepts that continue to defy a fixed definition and have been, and continue to be, subject to controversy. Should environmental issues be "securitized"? Defining environmental security can engage an intersectional approach, as the definition of environmental security encapsulates a competition for power about whose priorities and values are heard - the one who is able to define environmental security can further inform practices and policies, including such policies as the COP Paris Agreement of 2015. Which definition of environmental security is employed can mean the difference between the extent to which fossil fuel industries continue to extract oil and gas reserves to the detriment to environments and sociopolitical communities, or if such activities can be controlled based on a broader understanding of security that includes indigenous and gender-based (eco-feminism) priorities (Ingólfsdóttir 2016).

In what ways is the environment related to humans and human security, if at all, and in what ways are such connections perceived as legitimate (and by whom)? Security is, even amongst many critical security studies scholars, a concept that embodies an understanding of immediate threats that requires urgent action, and such immediacy is often not clear and present when it comes to the environment (Buzan et al. 1998). Due to the history of security concept, environmental security has often been "militarized" and masculinized through the addition of conflict scenarios arising from environmental catastrophes or degradation (Homer-Dixon 1991, 1994), though the thesis has been heavily critiqued (Gleditsch 1998). Many scholars acknowledge that "securing" the status quo of today's western lifestyles is largely contrary to the goals of "securing" the environment, while sustainable development, often characterized as ecological security, suggests that current modernization practices are not sustainable, and therefore a possible threat to security (Krause/Williams 2003). Economic development and the environment, both important to security, are pitted against one another, and little in the way of a solution appears in sight.

In the Arctic, economic security cannot be completely isolated, for example, from environmental security or political security. Food security is connected to environmental, health, and economic security, and so on. Even if we restrict ourselves to environmental security and never mind human or energy security, for example by concerning ourselves only with the environmental (atmospheric and oceanic) linkages between the polar climates and the rest of the planet, these too are extremely complex and non-linear in their relationship (SCAR 2005). They also 
give an incomplete picture without the complexity of the social and political dimensions brought in by human beings.

Examining environmental security in relation to human and ecological security (which prioritizes environmental protection and preservation) moves environmental security away from its masculinist and culturally western state-based roots (defending a destructive modern way of life, propagating environmentally destructive activities through traditional security mechanisms such as the military, etc) and reflects both the mounting concerns about environmental degradation, as well as emphasizes the importance of human relationships to the environment, prioritizing an intersectional focus. Both approaches are necessary to a more effective understanding of environmental security - ecological security stresses the interconnectedness of all elements within an ecological system, both how they impact as well as are impacted by the system. A "widened" environmental security approach brings the ecological and the human together: " $\ldots$ reformulate environmental security in terms of human security and peace, and drawing on the insights of ecological security" (Barnett 2001: 122). Humans are not only threatened by environmental threats, but cause them as well. A gender, and better yet intersectional, analysis, can illustrate this as a struggle between masculinized values of exploitation and feminized values of protection. As emphasized in the 2004 AHDR gender chapter, the ways in which humans interact and understand the systems in which they exist can differ substantially. Thus we have competing views of security.

An intersectional analytical approach has the ability to transcend and integrate many of the levels and sectors of security that scholars have otherwise chosen to analyze separately. Instead of playing into the dominant approaches to security studies which focus on a very small portion of the security grid and from the top down, gender analysis takes its starting point from the bottom up; it reaches all the way down to the individual, as gender analysis acknowledges that even the personal is political, and reflexive where the researcher is also a part of the system, and therefore the individual's experience is relevant. At the same time it is recognized that individuals are part of communities, and that gender is a significant feature of individual identity in relation to others and is therefore a part of societal security (Hoogensen and Rottem 2004). The social constructions of gender come in to play in the analysis, and the ways in which humans have constructed their societies on the basis of gender roles, who has the "right" to play which roles in the society, and how people are supposed to relate to one another. Intersectional analysis has demonstrated not only the dominance of male or patriarch-based societies, but culturally dominant societies, where the gendered demands (for example, Western feminists) of one society are imposed upon other, less dominant societies. Such processes have and continue to take place in the Arctic.

Intersectional approaches have a logical place in the human security discussion, bringing the political "down" to the level of the individual, to bring a voice to the personal. The personal is political, and human security, with its focus on the individual, has the potential to support these personal voices. Discourses and practices are made visible - by looking within, through, behind (closed doors) and beyond those in power - be they the state or powerful research practices and institutions, 
multiple actors come into view, including those who are often marginalized. Thus intersectionality in the Arctic, which also includes non-western approaches, highlights features of the security dynamic which have been isolated, ignored, and made invisible because the realities of gender and "other" have not been acknowledged. Just as gender is not reduced to "women's issues" in the Arctic, women in the Arctic are not reduced to a unified, monolithic whole, and men and women of the Arctic experience different forms of in/security on the basis of a combination of complex factors. Many of these factors are related to the environment, where livelihoods ranging from industrial to traditional rely upon as well as impact the natural environment. Indigenous women in the North West Territories, for example, may experience insecurities related to impacts of settler colonial relations in combination with economic insecurities generated by lack of opportunities in local economies for men in their families, which in turn exacerbates rates of domestic violence as well as suicides (Irlbacher-Fox 2015). Questions regarding priorities and values about "why it should be preferable to engage in short-term destructive mining activities at the cost of long-term sustainable economies already existing in the North" (Retter 2015) require analysis about the values within the cultures that compete for power in communities - both settler and indigenous. These values are in part expressed through systems that privilege those who adopt a masculinist, and racist, system of knowledge and power. To be able to dismantle this power, we need to understand it, and understand our role in it as researchers.

\subsection{Concluding Remarks}

This chapter has provided a brief overview of what it means to move from gender awareness to intersectional analysis, as well as a small snapshot of some of the security issues in the Arctic, moving away from traditional security perspectives. Security is examined from the margins or from positions of non-dominance through an intersectional approach. The Arctic is rife with examples of both marginalized regions (although each of the eight countries of the Arctic treat such regions quite differently), with an important focus upon the fact that the entire Arctic is a region inhabited by those who have traditionally been placed at the margins - the indigenous peoples. The experiences in the Arctic are varied, and the (in)securities in one part of the region are not necessarily the same in another part. However there are enough similarities to argue for attention to be drawn to this region and examine how people live and cope in a region with significant and special challenges. The Arctic demonstrates the importance of the environment and the human relationship with the environment to security, particularly human and societal securities with regard to traditional versus market economies, culture and identities based on relations with environment from fisheries communities to indigenous communities, health and food securities - which by their complexity demand intersectional analyses to be better understood. 


\section{References}

Ackerly BA, Stern M, True J (2006) Feminist methodologies for international relations. In: Ackerly BA, Stern M, True J (eds) Feminist methodologies for international relations. Cambridge University Press, Cambridge, pp 1-15

Agathangelou AM, Turcotte H (2008) Feminist methodologies for international relations. Politics Gend 4(1):184-187

Barnett J (2001) The meaning of environmental security: ecological politics and policy in the new security era. Zed Books, London

Buzan B, Wæver O, de Wilde J (1998) Security: a new framework for analysis. In: Boulder. Lynne Rienner Publishers, London

Crenshaw K (1991) Mapping the margins: intersectionality, identity politics, and violence against women of color. Stanford Law Rev 43(6):1241-1299

Einarsson N, Larsen JN, Nilsson A, Young OR (eds) (2004) Arctic human development report (AHDR). Stefansson Arctic Institute, Akureyri

Gleditsch NP (1998) Armed conflict and the envi-ronment: a critique of the literature. J Peace Res 35(3):381-400

Gray GC (2017) Academic voice in scholarly writing. Qual Rep 22(1):179-196

Health, M. o. S. A. a (2002) In: Tohka L (ed) Taking wing conference report: conference on gender equality and women in the Arctic. Ministry of Social Affairs and Health, Helsinki

Homer-Dixon TF (1991) On the threshold: environmental changes as causes of acute conflict. Int Secur 16(2):76-116

Homer-Dixon TF (1994) Environmental scarcities and violent conflict: evidence from cases. Int Secur 19(1):5-40

Hoogensen Gjørv G, Bazely DR, Goloviznina M, Tanentzap AJ (eds) (2014) Environmental and human security in the Arctic. Routledge, London

Hoogensen Gjørv G (2017) Tensions between environmental, economic, and energy security in the Arctic. In: Fondahl G, Wilson G (eds) Northern sustainabilities: understanding and addressing change in a circumpolar world. Springer International Publishing, Cham

Hoogensen G, Rottem SV (2004) Gender identity and the subject of security. Security Dialogue 35(2):155-171

Ingólfsdóttir A (2016) Climate change and security in the Arctic: analysis of norms and values shaping climate policy. $\mathrm{PhD}$

Irlbacher-Fox S (2015) Political participation of women in the northwest territories (NWT), Canada. In: Oddsdóttir E, Sigurdsson AM, Svandal S (eds) Gender equality in the Arctic: current realities, future challenges conference report. Ministry for Foreign Affairs, Reykjavik

Kawarazuka N, Locke C, McDougall C, Kantor P, Morgan M (2017) Bringing analysis of gender and social-ecological resilience together in small-scale fisheries research: challenges and opportunities. Ambio 46(2):201-213

Krause K, Williams MC (2003) Critical security studies. Routledge, London

Keating M, Della Porta D (2010) In defence of pluralism in the social sciences. Eur Political Sci 9:S111-S120

Larsen JN, Fondahl G (eds) (2014) Arctic human development report: regional processes and global linkages. Norden, Copenhagen

Marfelt MM (2016) Grounded intersectionality: key tensions, a methodological framework, and implications for diversity research. Equality, Divers Inclusion: An Int J 35(1):31-47

Miller GE (2004) Frontier masculinity in the oil industry: the experience of women engineers. Gend Work Organ 11(1):47-73

Oddsdóttir E, Sigurdsson AM, Svandal S (eds) (2015) Gender equality in the Arctic: current realities, future challenges conference report. Ministry for Foreign Affairs, Reykjavik

Retter G-B (2015) Sustainability and development in the Arctic. In: Oddsdóttir E, Sigurdsson AM, Svandal S (eds) Gender equality in the Arctic: current realities, future challenges conference report. Ministry for Foreign Affairs, Reykjavik 
SCAR (2005) SCAR Report: No 24, International Council for Science, Editor. Scientific Committee on Antarctic Research, Scott Polar Research Institute: Cambridge

Skjelsbæk I, Smith D (eds) (2001) Gender, peace and conflict. Sage, London

Walt SM (1991) The renaissance of security studies. Int Stud Q 35(2):211-239

World Bank Group (2015) Gender and the extractive industries: an overview, in energy and extractives. World Bank: https://olc.worldbank.org/sites/default/files/WB_Nairobi_Notes_1_ RD3_0.pdf

Open Access This chapter is licensed under the terms of the Creative Commons Attribution 4.0 International License (http://creativecommons.org/licenses/by/4.0/), which permits use, sharing, adaptation, distribution and reproduction in any medium or format, as long as you give appropriate credit to the original author(s) and the source, provide a link to the Creative Commons license and indicate if changes were made.

The images or other third party material in this chapter are included in the chapter's Creative Commons license, unless indicated otherwise in a credit line to the material. If material is not included in the chapter's Creative Commons license and your intended use is not permitted by statutory regulation or exceeds the permitted use, you will need to obtain permission directly from the copyright holder. 